\title{
Effect of Medial Branch Block in Chronic Facet Joint Pain for Osteoporotic Compression Fracture: One Year Retrospective Study
}

\author{
Ki Deok Park, MD ${ }^{1}$, Haemi Jee, $\mathrm{PhD}^{2}$, Hee Seung Nam, $\mathrm{MD}^{3}$, Soo Kyoung Cho, MD ${ }^{4}$, \\ Hyoung Seop Kim, $\mathrm{MD}^{5}$, Yongbum Park, $\mathrm{MD}^{6}$, Oh Kyung Lim, $\mathrm{MD}^{1}$
}

\begin{abstract}
${ }^{1}$ Deaprement of Rehabilitation Medicine, Gil Hospital, Gachon University of Medicine and Science, Incheon; ${ }^{2}$ Department of Health \& Fitness Management, Namseoul University, Cheonan; ${ }^{3}$ Department of Rehabilitation Medicine, Roihospital, Seoul; ${ }^{4}$ Department of Rehabilitation Medicine, SRC Hospital, Gwangju; ${ }^{5}$ Department of Rehabilitation Medicine, National Health Insurance Corporation Ilsan Hospital, Goyang; ${ }^{6}$ Department of Rehabilitation Medicine, Inje University Sanggye Paik Hospital, Inje University College of Medicine, Seoul, Korea
\end{abstract}

Objective To evaluate the outcomes of medial branch block in facet joint pain for osteoporotic compression fracture and utilize multiple regression, the relationship between their impact on treatment outcome and other factor, such as the radiologic finding, clinical parameters was analyze.

Methods Fifty-three patients with axial back pain from osteoporotic compression fracture were enrolled. The clinical outcomes were measured by Verbal Numeric Rating Scale (VNS) and Oswestry Disability Index (ODI) before treatment, 2 weeks, 3 months, and 12 months after the medial branch block. Radiographic analysis included measurement of overall sagittal alignment, collapsed vertebral height, and vertebral kyphotic angle. After 12 months, patients' satisfaction was classified to five categories: excellent, good, fair, poor or fail. Statistical analysis of both radiographic and clinical parameters along with treatment outcome was performed to determine any significant correlations between the two.

Results VNS and ODI was improved 2 weeks after the injection and continued to improve until 12 months. Significant improvement with significant pain relief $(>40 \%)$, functional improvement $(>20 \%)$, and the patients rated their satisfaction level as "excellent" or "good" at 12 months after the first injection were observed in $78.9 \%$. The radiographic and clinical parameters were not significantly correlated with treatment outcome.

Conclusion Our retrospective study demonstrated that the medial branch block provided significant pain relief and functional recovery to the patients with osteoporotic spinal compression fractures complaining of continuous facet joint pain after vertebroplasty or conservative treatment. A placebo-controlled prospective randomized double-blind study should be conducted in the future to evaluate the treatment effects.

Keywords Compression fractures, Osteoporotic fractures, Spinal injections

Received January 11, 2012; Accepted August 28, 2012

Corresponding author: Yongbum Park

Department of Rehabilitation Medicine, Inje University Sanggye Paik Hospital, 1342 Dongil-ro, Nowon-gu, Seoul 139-707, Korea

Tel: +82-2-950-1390, Fax: +82-2-935-3076, E-mail: swc328@naver.com

@ This is an open-access article distributed under the terms of the Creative Commons Attribution Non-Commercial License (http://creativecommons.org/ licenses/by-nc/3.0) which permits unrestricted noncommercial use, distribution, and reproduction in any medium, provided the original work is properly cited. Copyright (๑) 2013 by Korean Academy of Rehabilitation Medicine 


\section{INTRODUCTION}

Osteoporotic vertebral compression fractures (OVCFs) is the most common disease among bone fractures caused by osteoporosis. The volume and contents of the bony tissue decrease and the vertebral body is easily broken by a weak impact during daily living activities [1]. Due to an increase in the elderly population, OVCFs have been gradually increasing. Although various treatments have been conducted to treat OVCFs, a surgical treatment is difficult to conduct as most patients are elderly and have a state with high medical co-morbidities. In addition, a spinal fusion with instrumentation is required in the case of the surgical treatment, it is difficult to achieve its fixation effect due to osteoporosis. Furthermore, as the surgical treatment has disadvantages such as longer anesthesia, high risks of postoperative complications and relatively low success rate of bone union by bone graft, conservative treatment (analgesic treatment, orthosis use, and physical therapy) have been alternatively conduced [2].

In the recent days, a less extensive and minimally invasive surgical procedure (percutaneous vertebroplasty and kyphoplasty), which not only allows pain reduction but also a safer cement augmentation and achieve the stability of the vertebral body, is preferred [3]. When this treatment was conducted, it was reported that pain reduction was achieved and mobility was improved in approximately $90 \%$ of the patients who underwent percutaneous vertebroplasty within 24 hours after the surgery [4]. In the case of persistent axial back pain after vertebroplasty, however, it is not attributable to the vertebral body but to other reasons. In general, the vertebral body is a cause for pain in patients with acute compression fracture. As the structural deformity of the vertebra after fracture imposes more weight load on the facet joint, arthritis following fracture could be an important reason for pain in patients with vertebral fracture [5]. In addition, old compression fracture is incidentally observed in elderly patients with back pain in some cases. In this case, pain is also likely to be attributable to other factors such as facet joint, muscle, and tendon rather than the vertebral body [6]. It was reported that steroid injection at the facet joint was effective in the treatment of chronic facet joint pain in patients with thoracolumbar or lumbar compression fracture who underwent conservative treatment or verte- broplasty [5].

This study was conducted on patients who were followed-up for one year after medial branch block among those who had chronic facet joint pain following OVCFs. The correlation of the effect of medial branch block with patient satisfaction and radiological status such as local vertebral curvature and the sagittal alignment of the spine that might affect the treatment result with the clinical features of the patients were investigated.

\section{MATERIALS AND METHODS}

\section{Subjects}

This study was conducted on patients who visited the department of rehabilitation of Sanggye Paik Hospital due to thoracolumbar or lumbar axial pain, bilateral or unilateral hip pain, and referred pain of the low extremities from January 2009 to November 2011. Among the total 251 patients, those who had persistent pain 3 months after the surgery or who were diagnosed with old compression fracture located at the pain site by lumbar computed tomography, magnetic resonance imging, and radiology or who had osteoporosis ( $\mathrm{T}=-2.5$ or lower) were selected as the subjects. Among the subjects, 89 patients, except for those who had radiculopathy, spinal cord injury, cauda equina syndrome, or multiple facet joint pain caused by multiple facture, were selected, of whom the study was conducted on the 53 subjects who were diagnosed with thoracolumbar or lumbar facet joint pain as they had Verbal Numeric Rating Scale (VNS) that decreased $80 \%$ or more after diagnostic medial branch block conducted on the sites of vertebral segment of vertebroplasty or old compression fracture, and who underwent therapeutic medial branch block and then followed-up for one year or longer.

\section{Methods}

\section{Thoracolumbar or lumbar medial branch block}

All the medial branch blocks were performed utilizing a posterior approach with the patient in the prone position with a pillow under the chest.

For 1-4 medial branch block, in which the outline of the "scotty dog" is clearly evident, a puncture point is selected by placing the tip of the needle on the skin directly in line, along the X-ray beam, with the target point behind the "eye" of the dog $[7,8]$. Insertion is terminated 
once the tip of the needle strikes bone and this should be on the neck of the superior articular process, superodorsal to the silhouette of the transverse process [8]. Correct placement is confirmed by obtaining a posterioranterior view, in this view the tip of the needle should be at least opposite the lateral margin of the superior articular process. Once the needle is in correct position, the bevel should be directed caudally so as to avoid spread of the injectate to the intervertebral foramen $[7,8]$. This having been done, $0.2 \mathrm{~mL}$ of the non-ionic contrast medium Omnipaque300 (GE Healthcare, Carrigtohill, Ireland) can be injected to test that venous uptake dose not occur and if it does, the needle must be re-adjusted by $1-2 \mathrm{~mm}$ and the test repeated [8]. If there is no venous uptake, $1 \%$ lidocaine HCL $0.5 \mathrm{~mL}$ is injected onto the target nerve.

For L5 dorsal ramus block, the protocol is the same as for block at higher levels. The difference that obtain are that the target nerve is not the medial branch but the dorsal ramus itself and that target point is the junction of the ala of the sacrum with superior articular process of the sacrum [7-10].

For blocks of the T11 and T12 medial branches, the technique is the same as that for lumbar medial branch blocks (Fig. 1) [8]. A seemingly minor anatomical point is

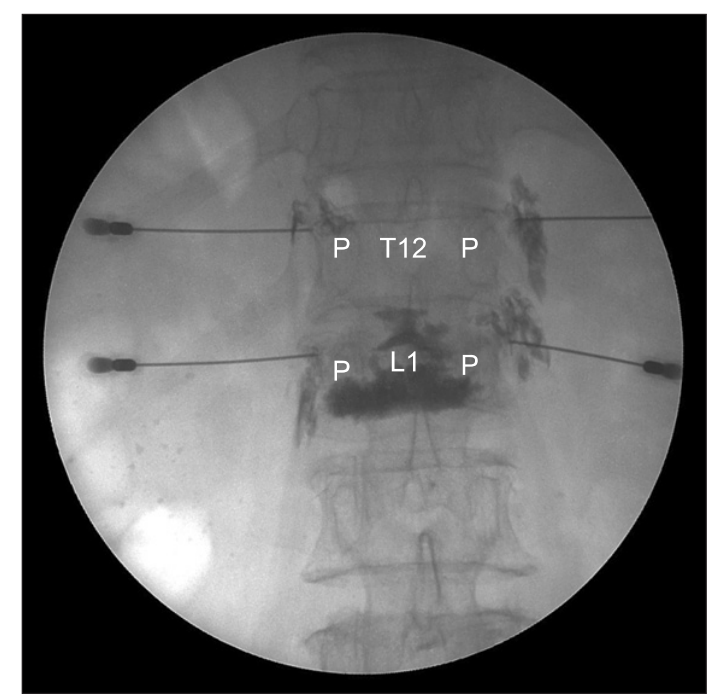

Fig. 1. T11, T12 medial branch block in patient with L1 compression fracture (vertebroplasty state). The T12-L1 joint is the medial branch of the T11 and T12 dorsal ramus. Anteroposterior radiography of contrast medium injected onto the target point for T11 and T12 medial branch blocks. The needle tip point to the contrast medium at the site for T11 and T12 medial branch blocks on the $\mathrm{T} 12$ and $\mathrm{L} 1$ superior articular processes. P, pedicle. of critical importance for accurately recording and communicating thoracic medial branch blocks. The segmental number of the nerve is the same as the number of the vertebral from under which its parent dorsal ramus and spinal nerve issues. When medial branches subsequently cross a transverse process, it will be the transverse process of the vertebral with the next segmental number, thus, the Tm medial branch will cross the $T(m+1)$ transverse process. Each medial branch innervates the zygapophysial joint of its own segment ant the one below. Thus the Tm medial branch innervates the $\mathrm{Tm}-\mathrm{T}(\mathrm{m}+1)$ joint and the $\mathrm{T}(\mathrm{m}+1)-\mathrm{T}(\mathrm{m}+2)$ joint. Conversely, the $\mathrm{Tm}-$ $\mathrm{T}(\mathrm{m}+1)$ joint is innervated by the $\mathrm{T}(\mathrm{m}+1)$ and $\mathrm{Tm}$ medial branches [8].

Repeated medial branch block was indicated if the VNS measured before injection increased $50 \%$ or more. As the frequency of therapeutic medial branch block using steroid and local anesthetic agent is allowed up to 6 times for one year based on the results of previous studies and the treatment guideline [11-13]. The conduct frequency was limited to up to 6 times in this study.

\section{Outcome assessment}

VNS was measured before the treatment, and 2 weeks, 3 months, and 12 months after the treatment to assess the effect of injection treatment. The VNS was obtained at 2 weeks and 12 weeks after the procedures to grade the treatment effects. When using VNS, the patients were asked to rate their pain on a scale from 0 to 10: 0 and 10 represented "no pain" and "the worst pain possible," respectively, in whole number with 11 integers including zero. A medical investigator marked the scale for the patients incapable of marking for themselves by directing and slowly moving from 0 to 10 on a VNS scale board. The patients nodded at the appropriate score.

The Korean version of Oswestry Disability Index (ODI) (Appendix 1), which was standardized to have 9 items by Kim et al. [14], was used for the severity of physical disability. Each item has a 6-point scale ranging from 0 to 5 points. Back pain is severer in proportion to the score. The total score is calculated by summing the scores of the 9 items, and expressed as percentage (\%). There are 4 subgroups mild $(0 \%-20 \%)$, moderate $(21 \%-40 \%)$, severe (41\%-60\%), and highly severe impairment $(60 \%$ or more) according to the percentage of the score [15].

Patient satisfaction levels were measured with a 5-point scale $(<0$, no effect at all; 1 , bad; 2 , fair; 3 , good; $\geq 4$, excel- 
lent) at 12 weeks. 'Excellent' was defined as satisfied with the treatment result as expected; 'good' was defined as, not as satisfied as expected but willing to try this treatment next time when pain redevelops; 'fair' was defined as had some effect but not enough to choose the same treatment next time when pain redevelops; and 'bad' was defined as the same effect with prior treatment or worse [16].

\section{Correlation of the treatment effect with various factors}

Successful treatment occurred when patients obtained significant pain relief (as measured by $>40 \%$ improvement in the VNS score and $>20 \%$ improvement in the ODI score) and reported a patient satisfaction score of 3 or 4 points at 12 weeks after the injections [17-19].

Body mass index $\left(\mathrm{kg} / \mathrm{m}^{2}\right)$ was 7 measured using the age, height, and weight of the patients. The previous history of systemic diseases such as diabetes, hypertension, and cardiac diseases were reviewed. As for the presence/ absence and status of osteoporosis, segments with old osteoporotic compression fracture between T12 and L5 or site that received vertebroplasty was excluded, and the bone density and t-score were obtained based on the mean bone density of the cancellous bone and cortical bone of the four region of the spinal segment, respectively, using peripheral quantitative computed tomography (p-QCT; Siemens, Erlangen, Germany).

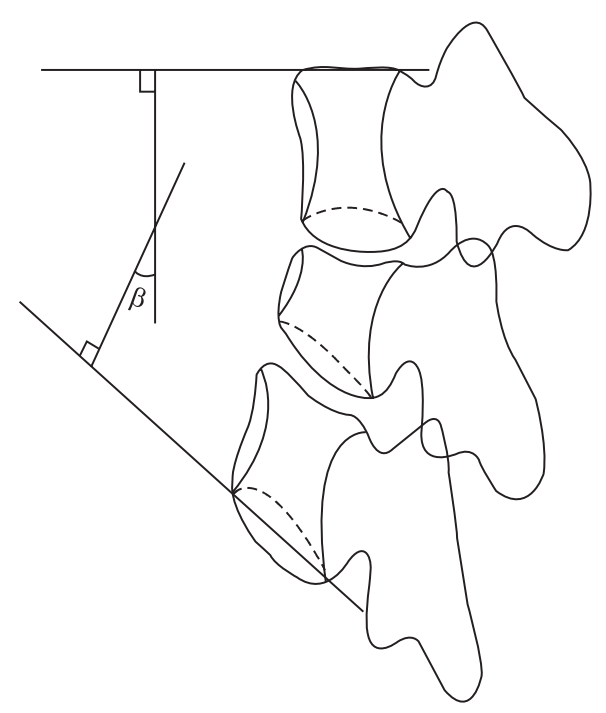

Fig. 2. The sagittal kyphotic angle of local segment was obtained by measuring the acute angle between the upper vertebral upper margin and lower vertebral lower margin of the collapsed vertebral body. $\beta$, measurement of the local kyphosis.
As for radiological examination before medial branch block, the anteroposterior and lateral region of standing full spine and standing lateral bending views of the lumbar spine including the hip joint and cervical vertebra were photographed using a $14 \times 36$ inch cassette. The sagittal kyphotic angle of local segment was obtained by measuring the acute angle between the upper vertebral upper margin and lower vertebral lower margin of the collapsed vertebral body (Fig. 2), the sagittal plane alignment was obtained by measuring the distance between $\mathrm{C} 7$ plumb line and anterior margin of S1. The compression fracture rate was calculated using the following equation: height loss=estimated prefracture heightpretreatment fractured height. The estimated prefracture height was applied by obtaining the mean value after summing the upper and lower vertebral body height of the adjacent fractured vertebral body [20]. All the results of radiological analysis were obtained by measuring three times by independent measurers and calculating the mean values. Subsequently, the correlation of the patient's status, radiologic parameters before injection, and the treatment effect was investigated.

\section{Statistical analyses}

At each time point, the VNS and ODI scores were compared using repeated measures analysis of variance (ANOVA), and Bonferroni corrections were utilized for post hoc comparisons. The treatment outcome and variables (patient's age, sex, duration of the disease, cause, radiologic finding) were compared with logistic regression analyses. All analyses were performed with SAS ver. 4.1 (SAS Institute Inc., Cary, NC, USA) with a significance level of $\mathrm{p}<0.05$.

\section{RESULTS}

\section{General characteristics of the patients}

A total of 53 subjects had the mean age of 68 years (range, 48 to 85 years), and BMI of $23.06 \mathrm{~kg} / \mathrm{m}^{2}$ (range, 17.6 to $26.8 \mathrm{~kg} / \mathrm{m}^{2}$ ). All the subjects were female patients and their mean pain duration was 7 months (range, 3 to 13 months). The radiologic parameters included mean compression rate $23.51 \%$ (range, $12.10 \%$ to $42.40 \%$ ), kyphotic angle $16.59^{\circ}$ (range, $10.6^{\circ}$ to $28.6^{\circ}$ ), and sagittal alignment $8.88 \mathrm{~cm}$ (range, 2.1 to $13.5 \mathrm{~cm}$ ) before the treatment (Table 1). 
Table 1. Characteristics of the patients

\begin{tabular}{lc}
\multicolumn{1}{c}{ Characteristic } & Patient (n=53) \\
\hline Age $(\mathrm{yr})$ & $68.42 \pm 9.60(48-85)$ \\
BMI $\left(\mathrm{kg} / \mathrm{m}^{2}\right)$ & $23.06 \pm 2.05(17.6-26.8)$ \\
Duration $(\mathrm{mo})$ & $7.00 \pm 2.61(3-13)$ \\
Numbar of injection & $3.26 \pm 1.11(1-6)$ \\
Past history & $8(15.1)$ \\
Diabetes mellitus & $17(32.1)$ \\
Hypertension & $6(11.3)$ \\
Smoking & $15(28.3)$ \\
Vertebroplasty & \\
Radiologic finding & $8.88 \pm 3.57(2.1-13.5)$ \\
Overall sagittal alignment $(\mathrm{mm})$ & \\
Collapsed vertebral height $(\%)$ & $23.51 \pm 5.84(12.10-42.40)$ \\
Vertebral kyphotic angle $\left({ }^{\circ}\right)$ & $16.59 \pm 4.18(10.6-28.6)$ \\
BMD (T score) & $3.55 \pm 0.73(2.50-5.40)$ \\
Level & $3(5.7)$ \\
T11 & $16(30.2)$ \\
T12 & $23(43.4)$ \\
L1 & $8(15.1)$ \\
\hline L2 & $3(5.7)$ \\
\hline L3
\end{tabular}

$\overline{\text { Values are presented as mean } \pm \text { standard deviation (range) }}$ or number (\%).

BMI, body mass index; BMD, bone mineral densitometry.

\section{Effect of medial branch block}

The mean frequency of medial branch block, average total relief over a period of 1 year, and average relief per procedure were $3.26,41.83$, and 13.26 weeks, respectively. The mean duration of average total relief over a period of 1 year, and average relief per procedure of each group according to the frequency of medial branch block are presented in Table 2.

The VNS scores and ODI scores were significantly reduced immediately after the treatment and remained reduced at 2 weeks, 3 months, and 12 months after the injections (Table 3 ).

The treatment effect was defined successful when the VNS and ODI increased $40 \%$ or more and ODI $20 \%$ or more, respectively, in the patients who had a patient satisfaction of 'gOdds ratioood' and 'excellent' in the 12-month follow-up. As a result, $100 \%, 81.1 \%$ (43 patients), and $78.9 \%$ (42 patients) of the patients showed the improved result 2 weeks, 3 months, and 12 months after the treatment.

\section{Correlation between the treatment effects and variables}

Successful treatment occurred when patients obtained significant pain relief (as measured by $>40 \%$ improvement in the VNS score and $>20 \%$ improvement in the ODI score) and reported a patient satisfaction score of 3 or 4 points at 12 weeks after the injections. Treatment success

Table 2. Therapeutic procedural characteristics over a period of one year

\begin{tabular}{cccc}
\hline No. of procedure in $\mathbf{1} \mathbf{~ y r}$ & No. of patients & Average relief per procedure (wk) & Average total relief (wk) \\
\hline 1 & 6 & 52 & 52 \\
2 & 10 & $21.32 \pm 3.94(16-23)$ & $43.34 \pm 5.71(35-52)$ \\
3 & 9 & $13.14 \pm 1.74(12-16)$ & $40.53 \pm 6.81(33-47)$ \\
4 & 22 & $10.83 \pm 2.12(9-14)$ & $42.42 \pm 4.83(29-52)$ \\
5 & 4 & $8.25 \pm 2.50(6-10)$ & $38.75 \pm 3.15(32-47)$ \\
6 & 2 & $7.40 \pm 2.10(7-9)$ & $47.00 \pm 2.00(45-49)$ \\
\hline Total (for 1 yr) & 53 & $13.26 \pm 6.24(5-52)$ & $41.83 \pm 7.42(29-52)$ \\
\hline
\end{tabular}

Values are mean \pm standard deviation (range).

Table 3. Effect on VNS and ODI 2 weeks, 3 months and 12 months after medial branch block

\begin{tabular}{lcccc}
\hline & Baseline & 2 wk after injection & 3 mo after injection & 12 mo after injection \\
\hline VNS & $7.23 \pm 0.52$ & $3.44 \pm 0.31^{\text {a) }}$ & $3.48 \pm 0.34^{\text {a) }}$ & $3.36 \pm 0.57^{\text {a) }}$ \\
ODI & $41.64 \pm 7.85$ & $23.29 \pm 5.16$ & $21.87 \pm 4.49^{\text {a) }}$ & $20.82 \pm 5.23^{\text {a) }}$ \\
\hline
\end{tabular}

Values are presented as mean \pm standard deviation.

VNS, Verbal Numeric Rating Scale; ODI, Oswestry Disability Index.

${ }^{a)} p<0.05$ (comparison of the before vs. after the injection). 
Table 4. Multiple logistic regression analysis for possible outcome predictors for injection effectiveness at follow-up

\begin{tabular}{|lccc}
\hline \multicolumn{1}{c}{ Factor } & Odds ratio & $\mathbf{9 5 \%}$ confidence interval & p-value \\
\hline Age $(\mathrm{yr})$ & 0.99 & $0.89-1.09$ & 0.81 \\
\hline Smoking & 1.96 & $0.17-22.08$ & 0.59 \\
\hline Body mass index $\left(\mathrm{kg} / \mathrm{m}^{2}\right)$ & 0.62 & $0.36-1.06$ & 0.08 \\
Bone mineral density $(\mathrm{T}$ score) & 0.57 & $0.19-1.77$ & 0.33 \\
\hline Hypertension & 0.86 & $0.17-4.40$ & 0.85 \\
\hline Diabetes mellitus & 0.56 & $0.08-3.94$ & 0.56 \\
\hline Vertebroplasty & 0.69 & $0.10-4.68$ & 0.70 \\
\hline Duration $(\mathrm{mo})$ & 1.13 & $0.83-1.56$ & 0.44 \\
\hline Overall sagittal alignment $(\mathrm{mm})$ & 0.94 & $0.75-1.19$ & 0.62 \\
\hline Collapsed vertebral height $(\%)$ & 1.07 & $0.93-1.25$ & 0.32 \\
\hline Vertebral kyphotic angle $\left({ }^{\circ}\right)$ & 1.02 & $0.81-1.29$ & 0.85 \\
\hline
\end{tabular}

was unrelated to the disease duration, the age, sex of patients and radiologic finding (Table 4).

\section{Complications}

No major complication was observed during the treatment. Dizziness and transient muscle weakness were observed in six patients after injection treatment, but they were completely resolved when the patients were discharged. Hot flash was observed in 2 patients, but it was resolved 2 weeks later. No other complication occurred.

\section{DISCUSSION}

The facet joint are true synovial joints with a joint space, hyaline cartilage surfaces, a synovial membrane, and a fibrous capsule. Lumbar facet joints are innervated with nociceptive fibers (pain-sensing nerves). As the nerve fibers, which contain the pain-mediator substance $\mathrm{P}$, and calcitonin gene-related peptide, have been isolated in the joint capsules and degenerative facet joint subchondral bone, overload of this richly innervated capsule potentially causes pain transmitted by means of nociceptive nerves [21]. Facet joint syndrome is clinically present, and pain can be blocked by diagnostic block [21]. spinal fracture may cause pain at the upper and lower areas of fracture by vertebral body collapse, spinal instability, facet joint syndrome, nerve compression, and kyphosis after spinal surgery [5].

Although the biomechanical effect of lumbar thoracolumbar compression has not yet been completely elucidated, a previous study using cadaver reported that the anterior compression fracture of the vertebral body increased thoracolumbar bending moment and subsequently thoracolumbar kyphosis, thereby increasing stress in the posterior structure of the spine including facet joint. Kim et al. [22] reported that concurrent facet joint pain was observed in $\mathbf{8 8 \%}$ of the patients due to body weight load caused by vertebral body compression fracture, and that dull pain with the unclear boundary along the rib and significant discomfort during wake up were observed even after vertebroplasty or kyphoplasty if medial branch block was not conducted.

Regarding the effect of medial branch block on facet joint pain, a double-blind randomized study, which was conducted by Manchikanti et al. [23], reported that $85 \%$ of patients with lumbar facet joint pain who received bupivacaine and steroid showed a pain relief of $50 \%$ or more and functional improvement of $40 \%$ or more in a one-year follow-up, and that pain relief was observed for 44-45 weeks/year in three or four times of injection treatments per year. The effect of steroids that was used for medial branch block against facet joint pain may be expressed as anti-inflammation, immunosuppression, anti-edema, and inhibition of neurotransmission in the C nerve fiber [24,25]. The use of a local anesthetic agent has long-term blocking effects achieved by suppression of nociceptive discharge, the blockade of sympathetic reflex arc, the blockade of axonal transport, the blockade of sensitization , and anti-inflammatory effects [26-30].

Georgy et al. [6] conducted a retrospective study and reported that of 144 patients who received vertebroplasty or sacroiliac joint surgery, 34 patients further underwent epidural steroid injection, facet arthritis injection, sacroiliac joint injection, trigger point injection due to 
persistent pain. They also reported that in addition to vertebral compression fracture, thoracolumbar pain was also caused by other spinal structures such as the disc, muscle, tendon, ligament, and facet joint [6]. Mitra et al. [5] reported that facet joints may be abnormally stressed due to the increasing thoracic flexion. In anterior compression fractures, which may serve as a secondary pain generator; intra-articular facet blocks may be an alternative to vertebroplasty. In this study, medial branch block was conducted on the patients who complained of persistent pain at the old compression fracture site or the patients with osteoporotic vertebral compression fractures (OVCFs) who complained of persistent pain after vertebroplasty. As a result, if the treatment effect was defined successful when the VNS and ODI increased $40 \%$ or more and ODI $20 \%$ or more, respectively, in the patients who had a patient satisfaction index of 'good' and 'excellent' in the 12-month follow-up, successful case was seen in $78.9 \%$ of the patient. In addition, The average procedures per year were 3.26 with an average relief per year of approximately 13.26 weeks per procedure and patients experiencing approximately 41, 83 weeks of relief during the period of 52 weeks with repeat blocks. Therefore medial branch blocks for OVCFs with chronic facet joint pain may be provide approximately 13.26 weeks of relief and requiring 3 to 4 episodes of treatment per year.

Until now, previous studies have reported that there are the correlation of the effect of conservative treatment or surgical treatment following vertebral compression fracture with various factors. Weinstein et al. [31] reported that pain was observed in $90 \%$ of 83 patients with thoracolumbar burst fracture who underwent conservative treatment, but it was insignificant, and that the pain severity was uncorrelated with the patient's age, gender, hospitalization duration, and duration of follow-up. Willen et al. [32] reported the mean kyphosis of $27^{\circ}$ and $19.5^{\circ}$ were formed after conservative treatment and surgical treatment, respectively, and that direct compression to the fractured site was correlated with pain in the case of a kyphosis formation of $30^{\circ}$ or more, but no correlation of treatment methods such as surgical or conservative treatment with patient pain was found. In this study, for the assessment of the treatment effect, the successful treatment effect was defined as a case of decrease in pain index $\geq 40 \%$ and function index $\geq 20 \%$ and patient satisfaction of 'good' or 'excellent'. Thus, no correlation of the treatment outcomes with patient's age, disease history, bone density, and radiological parameters was found. In this study, the mean kyphotic angle was shown to be $16.59^{\circ}$, which was insignificant compared to the result of the study conducted by Willen et al. [32] this is likely to be associated with the uncorrelation of the treatment effect. Reid et al. [33] reported that in the case of kyphotic angle $\leq 35^{\circ}$ in patients with thoracolumbar burst fracture without neurologic symptom, pain or working ability was satisfactorily improved and kyphosis did not increase.

Day and Kokan [34] reported that job change was required in approximately $67 \%$ of patients with the compression fracture rate $\geq 50 \%$. Meanwhile, Aglietti et al. [35] reported that approximately $80 \%$ of patients who underwent conservative treatments returned to their previous job. In this study, the mean severity of compression fracture rate was shown to be $23.51 \%$, and no case of $50 \%$ or more compression fracture rate was found. Thus, the patients were likely to have showed a good response to the conservative treatment, which showed no statistical correlation. In general, $50 \%$ or more compression fracture rate and kyphotic angle of $20^{\circ}$ or more increase the possibility of burst fracture. In these cases, a surgical treatment rather than a conservative treatment is preferably required due to the high frequency of posterior column injury [36].

In this study, medial branch block was performed if pain was persistent following vertebroplasty. Kim et al. [22] reported that facet joint block was recommended to be conducted before vertebroplasty or kyphoplasty. Facet joint block before vertebroplasty or kyphoplasty had two major roles, one was to let patients lie down during the procedure under the local anesthesia and the other was to let the operator find out the exact level among the multiple fractures by elimination of radiating pain to the flank, abdomen, groin or buttock. A further study is required to investigate the effect of medial branch block on compression fracture with facet joint pain by comparing the treatment group that underwent facet joint block before vertebroplasty with the control group.

This study has a few limitations. First, single diagnostic block of the lumbar medical branch using a single drug was conducted due to situations such as temporal and financial limitation and outpatient. However, in the case of uncontrolled single diagnostic block, the risk of false positivity was reported to be $38 \%$, which has a high pos- 
sibility of not completely ruling out discogenic pain or muscle pain [37]. Thus, this study was conducted at a response rate of $80 \%$ to rule out the false positivity. Second, this was a retrospective study which had various bias that may affect the treatment effect. Thus, a further prospective controlled study using a placebo is required. Nonetheless, this study is meaningful in that this was the first study that investigated the effect of medical branch block on chronic facet joint pain of compression fracture on a large scale. Considering the aforementioned limitations, a further prospective double-blind controlled study is required.

In conclusion, the result of this retrospective study showed that medial branch block resulted in the pain relief and functional recovery of the patients with OVCFs who complained of chronic facet joint pain following vertebroplasty or conservative treatment. A further prospective double-blind randomized controlled study is required to validate the results of this study.

\section{CONFLICT OF INTEREST}

No potential conflict of interest relevant to this article was reported.

\section{REFERENCES}

1. Bernstein J, Lane JM. Metabolic disorders of the spine. In: Rothman RH, Siemone FA, editors. The spine. 3rd ed. Philadelphia: WB Saunders; 1992. p. 1393-4.

2. Rapado A. General management of vertebral fractures. Bone 1996;18(3 Suppl):191S-196S.

3. Watts NB, Harris ST, Genant HK. Treatment of painful osteoporotic vertebral fractures with percutaneous vertebroplasty or kyphoplasty. Osteoporos Int 2001;12:429-37.

4. Garfin SR, Yuan HA, Reiley MA. New technologies in spine: kyphoplasty and vertebroplasty for the treatment of painful osteoporotic compression fractures. Spine (Phila Pa 1976) 2001;26:1511-5.

5. Mitra R, Do H, Alamin T, Cheng I. Facet pain in thoracic compression fractures. Pain Med 2010;11:16747.

6. Georgy BA. Interventional techniques in managing persistent pain after vertebral augmentation procedures: a retrospective evaluation. Pain Physician
2007;10:673-6.

7. Bogduk N. Evidence-informed management of chronic low back pain with facet injections and radiofrequency neurotomy. Spine J 2008;8:56-64.

8. Bogduk N. Practice guidelines for spinal diagnostic and treatment procedures. 1st ed. San Francisco: International Spinal Intervention Society; 2004. p. 47-65.

9. Bogduk N, Wilson AS, Tynan W. The human lumbar dorsal rami. J Anat 1982;134(Pt 2):383-97.

10. Bogduk N. The innervation of the lumbar spine. Spine (Phila Pa 1976) 1983;8:286-93.

11. Boswell MV, Shah RV, Everett CR, Sehgal N, McKenzie Brown AM, Abdi S, et al. Interventional techniques in the management of chronic spinal pain: evidencebased practice guidelines. Pain Physician 2005;8:1-47.

12. Manchikanti L, Staats PS, Singh V, Schultz DM, Vilims $\mathrm{BD}$, Jasper JF, et al. Evidence-based practice guidelines for interventional techniques in the management of chronic spinal pain. Pain Physician 2003;6:381.

13. Manchikanti L, Manchikanti KN, Manchukonda R, Pampati V, Cash KA. Evaluation of therapeutic thoracic medial branch block effectiveness in chronic thoracic pain: a prospective outcome study with minimum 1-year follow up. Pain Physician 2006;9:97-105.

14. Kim KT, Lee SH, Suk KS, Lee JH, Im YS, Seo EM. Loss of sagittal balance and clinical outcomes following corrective osteotomy for lumbar degenerative kyphosis. J Korean Orthop Assoc 2009;44:83-92.

15. Fairbank JC, Couper J, Davies JB, O'Brien JP. The Oswestry low back pain disability questionnaire. Physiotherapy 1980;66:271-3.

16. Lee IS, Kim SH, Lee JW, Hong SH, Choi JY, Kang HS, et al. Comparison of the temporary diagnostic relief of transforaminal epidural steroid injection approaches: conventional versus posterolateral technique. AJNR Am J Neuroradiol 2007;28:204-8.

17. Ng L, Chaudhary N, Sell P. The efficacy of corticosteroids in periradicular infiltration for chronic radicular pain: a randomized, double-blind, controlled trial. Spine (Phila Pa 1976) 2005;30:857-62.

18. Campbell WI, Kendrick RW. Pre-emptive analgesia using local anaesthesia: a study in bilaterally symmetrical surgery. Br J Anaesth 1997;79:657-9.

19. Nam HS, Park YB. Effects of transforaminal injection for degenerative lumbar scoliosis combined with spi- 
nal stenosis. Ann Rehabil Med 2011;35:514-23.

20. Ledlie JT, Renfro M. Balloon kyphoplasty: one-year outcomes in vertebral body height restoration, chronic pain, and activity levels. J Neurosurg 2003;98 Suppl 1:36-42.

21. Beaman DN, Graziano GP, Glover RA, Wojtys EM, Chang V. Substance P innervation of lumbar spine facet joints. Spine (Phila Pa 1976) 1993;18:1044-9.

22. Kim TK, Kim KH, Kim CH, Shin SW, Kwon JY, Kim $\mathrm{HK}$, et al. Percutaneous vertebroplasty and facet joint block. J Korean Med Sci 2005;20:1023-8.

23. Manchikanti L, Singh V, Falco FJ, Cash KA, Pampati V. Lumbar facet joint nerve blocks in managing chronic facet joint pain: one-year follow-up of a randomized, double-blind controlled trial: Clinical Trial NCT00355914. Pain Physician 2008;11:121-32.

24. Lee HM, Weinstein JN, Meller ST, Hayashi N, Spratt KF, Gebhart GF. The role of steroids and their effects on phospholipase A2: an animal model of radiculopathy. Spine (Phila Pa 1976) 1998;23:1191-6.

25. Johansson A, Hao J, Sjolund B. Local corticosteroid application blocks transmission in normal nociceptive C-fibres. Acta Anaesthesiol Scand 1990;34:335-8.

26. Arner S, Lindblom U, Meyerson BA, Molander C. Prolonged relief of neuralgia after regional anesthetic blocks: a call for further experimental and systematic clinical studies. Pain 1990;43:287-97.

27. Benzon HT. Epidural steroid injections for low back pain and lumbosacral radiculopathy. Pain 1986;24: 277-95.

28. Lavoie PA, Khazen T, Filion PR. Mechanisms of the inhibition of fast axonal transport by local anesthetics. Neuropharmacology 1989;28:175-81.
29. Katz WA, Rothenberg R. Section 3: The nature of pain: pathophysiology. J Clin Rheumatol 2005;11 Suppl 2:S11-5.

30. Cassuto J, Sinclair R, Bonderovic M. Anti-inflammatory properties of local anesthetics and their present and potential clinical implications. Acta Anaesthesiol Scand 2006;50:265-82.

31. Weinstein JN, Collalto P, Lehmann TR. Thoracolumbar "burst" fractures treated conservatively: a longterm follow-up. Spine (Phila Pa 1976) 1988;13:33-8.

32. Willen J, Lindahl S, Nordwall A. Unstable thoracolumbar fractures: a comparative clinical study of conservative treatment and Harrington instrumentation. Spine (Phila Pa 1976) 1985;10:111-22.

33. Reid DC, Hu R, Davis LA, Saboe LA. The nonoperative treatment of burst fractures of the thoracolumbar junction. J Trauma 1988;28:1188-94.

34. Day B, Kokan P. Compression fractures of the thoracic and lumbar spine from compensable injuries. Clin Orthop Relat Res 1977;(124):173-6.

35. Aglietti P, Di Muria GV, Taylor TK, Ruff SJ, Marcucci M, Novembri A, et al. Conservative treatment of thoracic and lumbar vertebral fractures. Ital J Orthop Traumatol 1983;9 Suppl:83-105.

36. Shin BJ, Kim SK, Lee BI, Kim YI, Rah SK, Choi CU. Posterior column injuries in thoracolumbar and lumbar burst fractures. J Korean Soc Spine Surg 1997;4:6773.

37. Schwarzer AC, Aprill CN, Derby R, Fortin J, Kine G, Bogduk N. The false-positive rate of uncontrolled diagnostic blocks of the lumbar zygapophysial joints. Pain 1994;58:195-200. 
Appendix 1. Oswestry Disability Index

This questionnaire has been designed to give us information as to how your back or leg pain is affecting your ability to manage in everyday life. Please answer by checking ONE box in each section for the statement which best applies to you. We realize you may consider that two or more statements in any one section apply but please just shade out the spot that indicates the statement which most clearly describes your problem.

\section{Section 1: Pain Intensity \\ a I can tolerate the pain I have without having to use pain killers. [0 points] \\ $\square$ The pain is bad but I manage without taking pain killers. [1 point] \\ $\checkmark$ Pain killers give complete relief from pain. [2 points] \\ $\checkmark$ Pain killers give moderate relief from pain. [3 points ] \\ $\checkmark$ Pain killers give very little relief from pain. [4 points] \\ a Pain killers have no effect on the pain and I do not use them. [5 points]}

\section{Section 2: Personal Care}

a I can look after myself normally without causing extra pain. [0 points]

a I can look after myself normally but it causes extra pain. [1 point]

$\square$ It is painful to look after myself and I am slow and careful. [2 points]

a I need some help but manage most of my personal care. [3 points]

a I need help every day in most aspects of self-care. [4 points]

a I do not get dressed wash with difficulty and stay in bed. [5 points]

\section{Section 3: Lifting}

व I can lift heavy weights without extra pain. [0 points]

a I can lift heavy weights but it gives extra pain. [1 point]

a Pain prevents me from lifting heavy weights off the floor but I can manage if they are conveniently positioned for example on a table. [2 points]

$\checkmark$ Pain prevents me from lifting heavy weights but I can manage light to medium weights if they are conveniently positioned. [3 points]

口 I can lift only very light weights. [4 points]

a I cannot lift or carry anything at all. [5 points]

\section{Section 4: Walking}

$\checkmark$ Pain does not prevent me walking any distance. [0 points]

$\checkmark$ Pain prevents me walking more than 1 mile. [1 point]

a Pain prevents me walking more than 0.5 miles. [2 points]

a Pain prevents me walking more than 0.25 miles. [ 3 points]

a I can only walk using a stick or crutches. [4 points]

a I am in bed most of the time and have to crawl to the toilet. [5 points]

\section{Section 5: Sitting}

a I can sit in any chair as long as I like. [0 points]

a I can only sit in my favorite chair as long as I like. [1 point]

a Pain prevents me sitting more than 1 hour. [2 points]

a Pain prevents me from sitting more than 0.5 hours. [3 points] 
a Pain prevents me from sitting more than 10 minutes. [4 points]

$\checkmark$ Pain prevents me from sitting at all. [5 points]

\section{Section 6: Standing}

a I can stand as long as I want without extra pain. [0 points]

a I can stand as long as I want but it gives me extra pain. [1 point]

a Pain prevents me from standing for more than 1 hour. [2 points]

a Pain prevents me from standing for more than 30 minutes. [3 points]

a Pain prevents me from standing for more than 10 minutes. [4 points]

$\checkmark$ Pain prevents me from standing at all. [5 points]

\section{Section 7: Sleeping}

a Pain does not prevent me from sleeping well. [0 points]

a I can sleep well only by using tablets. [1 point]

a Even when I take tablets I have less than 6 hours sleep. [2 points]

a Even when I take tablets I have less than 4 hours sleep. [3 points]

a Even when I take tablets I have less than 2 hours of sleep. [4 points]

a Pain prevents me from sleeping at all. [5 points]

\section{Section 8: Social Life}

a My social life is normal and gives me no extra pain. [0 points]

a My social life is normal but increases the degree of pain. [1 point]

a Pain has no significant effect on my social life apart from limiting energetic interests such as dancing. [2 points]

a Pain has restricted my social life and I do not go out as often. [3 points]

a Pain has restricted my social life to my home. [4 points]

a I have no social life because of pain. [5 points]

\section{Section 9: Traveling}

a I can travel anywhere without extra pain. [0 points]

a I can travel anywhere but it gives me extra pain. [1 point]

$\square$ Pain is bad but I manage journeys over 2 hours. [2 points]

a Pain restricts me to journeys of less than 1 hour. [3 points]

a Pain restricts me to short necessary journeys under 30 minutes. [4 points]

口 Pain prevents me from traveling except to the doctor or hospital. [5 points] 